Derecho \& Realidad

Núm. 23 • I semestre de 2014

Facultad de Derecho y Ciencias Sociales, UPTC

ISSN: 1692-3936

\title{
La medida cautelar innominada: antonomasia del acceso a la administración de justicia
}

\author{
The innominate injunction: quintessential \\ of the access to justice
}

María Juliana Jiménez Martínez - Diego Fernando Rodriguez Pardo Erick Esleider Santos Young - David Camilo Murillo Romero Geraldi Hernández Guzman - Diana Alejandra Galindo Cuadros Clara Natalia Rivera Estupiñan - Carolina Quintero Rodríguez Paula Andrea Quiroga Rodríguez - Fanny Mayerly Reyes* Edizon Gonzalo Porras López**

\section{Resumen}

El propósito de esta ponencia recae en poner de relieve la lógica jurídica y procesal a la que responde la medida cautelar innominada como instrumento de Justicia, de reivindicación procesal y credibilidad social;concibiendo al proceso como un instrumento para llegar a la Justicia a través de la verdad, donde las medidas cautelares innominadas emanan de las exacciones y sed de legitimidad, de ejecutividad y de efectividad de las decisiones judiciales, proponiendo como resultado de esta, la extensión del sistema cautelar innominativo a los procesos contenciosos administrativos, mediante la ampliación de la potestad cautelar Genérica del juez, desarrollando un margen de discrecionalidad caracterizado por la proporcionalidad en la calificación de la medida, concluyendo que estas herramientas corresponden a la única

* Estudiantes de la Facultad de Derecho y Ciencias Sociales de la Uptc, semillero de investigación Derecho Procesal.

** Coordinador del semillero de investigación Derecho Procesal. 
forma de lograr el afianzamiento de la credibilidad social en la efectividad del cumplimiento de las sentencias, conclusiones extraídas medianteun método sistemático y explicativo.

\title{
Palabras clave
}

Tutelas cautelares judiciales, Efectividad, Justicia material, Acceso a la Administración de Justicia, Procedimiento Contencioso Administrativo.

\begin{abstract}
The purpose of this paper lies in highlighting the legal and procedural logic that responds precautionary measure as an instrument of justice, procedural claim and social credibility; perceiving the process as a tool to reach the Justice through the truth, where unnamed precautionary measures emanating from the exactions and thirst for legitimacy, enforceability and effectiveness of judicial decisions, proposing as a result of this, the extent of innominativo to administrative proceedings, by extending the authority of the judge Generic precautionary developing a discretion characterized by proportionality in the classification of the measure, concluding that these tools are the only way to achieve the strengthening of prudential system social credibility in the effectiveness of enforcement of judgments, conclusions drawn through a systematic and comprehensive method.
\end{abstract}

\section{Key words}

Pendent title injuctions, effectiveness, material justice, access to justice administration, administrative judicial procedure. 


\section{Introducción}

"Si todas las providencias jurisdiccionales son un instrumento del derecho sustancial que se actúa a través de ellas, en las providencias cautelares se encuentra una instrumentalidad cualificada, o sea elevada, por así decirlo, al cuadrado; son...en relación a la finalidad última de la función jurisdiccional, instrumento del instrumento"

Calamandrei

Se impone como precondición aceptar que si bien en el mundo hay desigualdades, estas deben desaparecer en el proceso judicial. Bajo ese tamiz es posible, entonces, abordar la tutela cautelar judicial, como instrumento que permite lograr seguridad jurídica y dispositividad razonable. Ahora bien, si aceptamos que las desigualdades materiales que hay en el mundo se comunican al proceso y en muchas ocasiones incrementadas superlativamente, debemos exigirle a alguien la morigeración de tamañas diferencias, lo cual implica el desplazamiento de la concepción de la igualdad abstracta hacia la idea de un verdadero equilibrio. Así mismo es apodíctico entender el proceso como experiencia de comunicación humana, por tanto, desarrollado entre personas, respecto de las cuales su fin es reducir al máximo las desigualdades, para que el sentido de la justicia se traduzca en un servicio, por su naturaleza de bien público puro, y la existencia del Estado mismo se explica como productor de bienes públicos, que a los privados deja indiferente por lo exiguo del beneficio. La justicia se provee entre las personas que no son iguales en la realidad y es ahí donde la tutela cautelar judicial permite atenuar tal situación. En este sentido, las medidas cautelares aparecen como herramientas procesales para soslayar el peligro de que la justicia deje en el camino su eficacia, sin la cual simplemente deja de ser justicia.

La estructura que sigue el presente escrito es la siguiente: inicialmente se hacen comentarios sobre (i) las medidas cautelares como garantías del acceso real a la administración de justicia, (ii) seguidamente se relaciona la naturaleza iusfundamental del acceso a la justicia en nuestro ordenamiento y se establece que las cautelas procesales son elementos integrantes de ese derecho, (iii) se hace una breve aproximación conceptual a las tutelas cautelares procesales, que incluye su clasificación, características y presupuestos para su aplicación, (iv) También se presenta una propuesta dirigida a enervar estas herramientas como ejemplo de justicia, donde tendrá especial lugar la necesidad de ampliar la potestad cautelar del juez en la extensión del sistema cautelar innominativo al proceso contencioso administrativo, (v) en último término, se exponen las conclusiones. 


\section{Las medidas cautelares como garantías del acceso real a la administración de justicia}

Las innegables desigualdades que rodean al ser humano exigen una garantía de protección de los derechos y de sanción a sus transgresores, para lo cual, se hace necesaria la intervención de los aparatos jurisdiccionales; además se examina la exigencia de seguridad jurídica, explicada por el profesor Alterini (1993, p. 15-17) como "la seguridad por medio del derecho, la seguridad como certidumbre del derecho y la seguridad como la estabilidad del derecho". A fin de alcanzar tal seguridad jurídica, es imprescindible que los derechos puedan hacerse efectivos, aun en contra de aquellos que pretenden desconocerlos o controvertirlos, y es ahí donde la eficacia de la administración de justicia encumbra su propósito en el respeto por los derechos dentro de los procesos tramitados ante esta; de manera que la mora en la tramitación y solución de los litigios hace que, en la práctica, el reconocimiento dado a los derechos en las sentencias sea inútil.

En esta medida y bajo la idiosincrasia de la moderna justicia constitucional (Pérez, 2000, p. 19), el honorable tribunal constitucional anota que

las medidas cautelares son instrumentos procesales para asegurarla efectividad de los derechos judicialmente declarados, y han sido consideradas como un componente del derecho de acceso a la administración de justicia, en virtud a (sic) que tal derecho comprende no solo la pretensión de obtener un pronunciamiento judicial en torno a los derechos, sino la materialización de las medidas que los hagan efectivos (Corte Constitucional, sentencia C-039, 2004).

Con ello se muestra la intersección del acceso a la justicia y las cautelas procesales, por su thelos común, que consiste en la obtención de una sentencia, que ponga fin al litigio, sin importar si esta favorece al accionante o al sujeto pasivo de la acción; una sentencia desligada del concepto de pretensión, que obliga a determinar si el instituto del proceso responde a la existencia de un derecho subjetivo sustancial que comporte una tutela jurisdiccional correlativa, dando lugar a la concepción de tutela cautelar judicial divisada en una triada sistemática de proceso, efectividad y justicia (Porras, 2011, p. 20-27), y no como muchos la aprecian, bajo un carácter eminentemente instrumental (Quiroga, 1991, p. 28-30).

En este punto es necesario resaltar que el acceso a la justicia, también conocido como derecho a la jurisdicción, inicialmente se encontraba ligado al concepto material de acceso a la justicia, que envolvía la mera posibilidad de demandar ante el Estado para que este se pronunciara frente al derecho en litigio; posteriormente se separó el concepto de derecho material y de derecho de acción concediendo a este último 
un contenido más amplio, en cuanto implica la consecución de una sentencia de carácter solidarista; y es en este punto que las medidas cautelares se ubican como enlace conciliador de celeridad y ponderación, que son las dos exigencias de la justicia, de manera que aquellas logran imprimir agilidad y efectividad al proceso, en el sentido que satisface el cumplimiento de las providencias judiciales (Chinchilla, 1991, p. 28). De la anterior aseveración surgen dos consideraciones principales, en primer lugar que las tutelas cautelares judiciales se encuadran como parte de la actividad jurisdiccional del Estado; y en segundo lugar, que las medidas cautelares solo pueden existir dentro del proceso, sin importar su naturaleza, pero bajo el marco de instancias procesales. Por consiguiente, estas medidas están llamadas a operar en el proceso, per se, los fenómenos que también cumplen funciones cautelares, pero cuya existencia permanece en el campo del derecho sustancial, como las garantías reales o personales para el aseguramiento de una obligación, que no pueden considerarse como tales; las que sí lo son, tienen la particularidad de que constituyen una forma autónoma de acción, ya que existen aun sin la certidumbre de la existencia del derecho, ergo, se circunscriben al desarrollo y continuidad del proceso. Por lo anterior, se puede afirmar, sin que exista contradicción en ello, que las medidas cautelares tienen un carácter autónomo e independiente (Salamanca, citado por Ardila, 1984, p. 279). Así pues, el ejercicio de la acción cautelar no es contemporáneo del derecho principal, es decir, no necesita del derecho material para surgir, puesto que a quien la ejerce no puede oponérsele la inexistencia de este último, y la oposición a la medida cautelar se funda en la ausencia de alguno de sus presupuestos propios, que son independientes del derecho principal, en virtud de la separación de derecho de acción con la pretensión, lo cual determina una reclamación dirigida a la contraparte y elevada ante el órgano encargado de administrar justicia (Porras, 2011). De esta forma, la tutela cautelar judicial constituye un mecanismo de defensa que el Estado reconoce en cabeza de los asociados en la defensa de sus derechos. En otras palabras, la facultad de obtener la cautela no es accesoria al derecho material, ya que la medida se puede lograr sin que en ese momento se sepa si se obtendrá la pretensión, pero su estructura sí está vinculada al proceso principal (Fabregá, 1998, p. 44-45).

Igualmente, la Corte Constitucional ha justificado la existencia de las medidas cautelares, señalando que ellas desarrollan el principio de eficacia de la administración de justicia, consagrando el derecho a la ejecución de la sentencia en firme, que radica en la materialización de las decisiones judiciales, exponiendo la aplicación del artículo 277 de la Constitución Política, el cual instituye como funciones del ministerio público, la de velar por el estricto cumplimiento de las providencias judiciales, y en similar tenor, el artículo 201 de la misma, establece que corresponde al presidente de la república en relación con la rama judicial "prestar a los funcionarios judiciales, con arreglo a las leyes, los auxilios necesarios para hacer efectivas sus providencias". 
Dadas estas reflexiones, se sostiene que las cautelas procesales son elementos integrantes del derecho de todas las personas a acceder a la administración de justicia, contribuyendo consecuencialmente a la igualdad procesal (Corte Constitucional, sentencia C-490, 2000). Esta misma corporación ha desarrollado metódicamente esos elementos al considerar:

i) que las decisiones de los jueces deben ser ejecutadas y cumplidas, ya que poco sentido tendría que los jueces resolvieran las controversias, pero sus decisiones resultaran inocuas en la práctica al no poder ser materialmente ejecutadas; ii) que todas las personas deben tener un acceso efectivo e igual a la justicia, y es obvio que ese acceso no debe ser puramente formal, por lo cual tiene derecho a que el ordenamiento establezca mecanismos para asegurar al efectividad de las decisiones judiciales que les son favorables; iii) que es necesario que el derecho al acceso a la justicia que contribuya a un mayor equilibro procesal, en la medida que asegure que quien acuda a la justicia mantenga, en el desarrollo del proceso, un estado de cosas semejante al que existía cuando recurrió a los jueces. (...). (Corte Constitucional, sentencia C-039, 2004)

Los tres propósitos anteriores se logran con las medidas cautelares, verdaderos instrumentos con los cuales el ordenamiento protege de manera provisional y mientras dura el proceso, la integridad de un derecho que es controvertido en ese mismo proceso.

\subsection{Naturaleza iusfundamental del acceso a la justicia en nuestro ordenamiento: las cautelas procesales son elementos integrantes de ese derecho}

En efecto, no se puede hablar de acceso real a la administración de justicia, si no existe una trasformación hacia el derecho reclamado, esjudem, “...las personas tienen derecho a acceder a la justicia y esto no se logra cuando, a pesar de existir una decisión judicial, las cosas siguen siendo iguales" (Moreno, 2000, p. 116). El cimiento novísimo del derecho de acceso a la administración de justicia se implanta en la obtención por parte del Estado de una solución justa y consciente de la realidad de los hechos debatidos como respuesta al conflicto derivado de relaciones intersubjetivas; una solución proferida por un ente con capacidad jurídica, revestido de imparcialidad y que resuelva sustancial y materialmente la controversia del $s u b$ lite. Para ello debe determinar un plazo razonable que contemple el momento procesal definitivo en el que con certeza las resoluciones que se profieran sean aptas para la concreción de los derechos, lo cual conduce a la existencia de mecanismos cautelares que aseguren la efectividad de las decisiones judiciales.

Ahora bien, el derecho a una tutela judicial efectiva se armoniza con el anhelo y la necesidad social de una administración de justicia caracterizada, entre otras notas 
distintivas, por su efectividad que, a la par de la observancia de la plenitud de las garantías procesales, signifique una respuesta más pronta y mucho más cercana en el tiempo a las demandas de los ciudadanos. Este exordio supone que la tardanza en la resolución de sus causas no genere incertidumbre sobre la eficacia de las decisiones judiciales, prescribiendo la obligatoriedad de un régimen de tutela cautelar judicial que garantice la realización efectiva y material de las sentencias y que los fallos de los jueces no sean ilusorios (Restrepo, 2006, p. 14-18).

Por otro lado, dentro del concepto de Estado social de derecho se encuentra comprendida la obligación del Estado de brindar instituciones y procedimientos a los asociados, para la solución de los conflictos; de manera que el incumplimiento de esa obligación del juez de garantizar el derecho fundamental de los ciudadanos de acceder a la justicia, ocasiona menoscabo en la defensa de sus derechos e intereses, o dicho en otros términos, produce indefensión judicial (Moreno, 2000). Infracción que, además de favorecer un inaceptable estado de indefensión, socava los fundamentos esenciales del mismo Estado, pues se entiende que las personas no solo tienen derecho al acceso a la administración de justicia para el ejercicio de sus intereses legítimos, sino también que dichas personas tienen derecho a obtener una tutela efectiva por parte de esos órganos administradores de justicia (Corte Constitucional, sentencia T-606, 2001). Es así como se hilvanan las cautelas procesales dentro del espectro de la tutela jurisdiccional efectiva que, como se reitera, tiene un campo más amplio que el simple acceso a jueces, tribunales, autoridades administrativas a través de un proceso, ya que esta se materializa con la aplicación de garantías constitucionales en el proceso mismo, las cuales permiten la efectividad y celeridad de una justicia procesal constitucional (Palomino, 2011, p. 33-47).

Lo anterior permite traer a colación la consecución de las siguientes garantías, vinculadas intrínsecamente al núcleo esencial del derecho de acceso a la administración de justicia, a saber (Porras, 2011):

- Igualdad a las partes (Corte Constitucional, sentencia C-221, 1992). El contenido del acceso a la justicia está profundamente vinculado con el contenido de los derechos fundamentales del debido proceso y la igualdad. "El derecho fundamental de acceso efectivo a la administración de justicia impone a los jueces el deber de actuar como celosos guardianes de la igualdad sustancial de las partes vinculadas al proceso" (Corte Constitucional, sentencia T-006, 1992). Igualdad que se refiere en primer lugar, (i) al concepto de igualdad ante la ley, partiendo obviamente de las desigualdades sociales existentes, y que se traduce en una igualdad de acceso a las instancias judiciales; (ii) igualdad de trato por las instancias judiciales, conforme al cual todas las personas que se encuentren en las mismas condiciones deben obtener la misma respuesta por la instancia 
judicial (Moreno, 2000), entendido este aspecto frente a la protección de los derechos fundamentales que se ven involucrados en el proceso y frete a la administración de justicia (Corte Constitucional, sentencia T-484, 1993). Ante tal argumento, se alzan las medidas cautelares en la égida de la igualdad y el equilibrio procesal, pues aseguran al justiciable mantener en el curso del proceso un estado de cosas semejante al que existía cuando acudió a la jurisdicción, y proporcionan dispositivos procesales para hacer frente a las maniobras maliciosas del infractor en el no acatamiento de la sentencia.

- Se arribe a una sentencia que garantice la realización de los derechos amenazados o vulnerados. Como se ha venido aludiendo, el acceso a la administración de justicia no se agota con la interposición o aplicación de los actos introductorios del proceso, por el contrario, el acceso a la justicia se desenvuelve durante todo el proceso y hasta la terminación del mismo, hasta llegar a una decisión razonada sobre los méritos del reclamo. Comprende por lo tanto:

a) La garantía de aplicación de un orden jurídico que entronice imparcialidad y adecuada valoración de las normas y valores involucrados. El juez juega un papel muy importante para garantizar el acceso a la justicia, pues este debe lograr la efectividad de los derechos reclamados, debe ser un juez director del proceso, pero además, y por sobre todo, un juez comprometido, esto es, un juez dinámico, que aplique los poderes inquisitivos y oficiosos que el estatuto procesal le otorga (Capograssi, 1950, p. 5), pero imparcial frente a los intereses de los contendientes, debe ser un protagonista de la aplicación de justicia, evitando a toda costa la alteración normal del proceso con vicios, nulidades etc., es decir, colaborando para llegar a una sentencia, que ponga fin al litigio, con una debida motivación desde el punto de vista formal, a partir de la aplicación correcta de las normas sustanciales y procesales; y, desde el punto de vista material, es decir la valoración en concreto de los demás valores involucrados (medios de prueba), (Corte Constitucional, sentencia C-084, 1995), que garanticen que la decisión sea lo más justa posible (Moreno, 2000). Así, las medidas cautelares imponen mayor protagonismo del juez, donde se vislumbra que un Estado social de derecho como el nuestro, no puede "prestar" cualquier clase de juez que dirima el conflicto como sea, sino un juez que resuelva con criterios que permitan hablar de justicia, y no cualquier clase de justicia, sino de una justicia material, y no cabe duda que para extraer tal activismo judicial se reclama dispositividad y oficiosidad, es decir, la necesidad de ampliar la potestad cautelar del juez.

b) Que la decisión sea lo más justa posible. "La validez y la búsqueda de la verdad, son objetos de la justicia (Corte Constitucional, sentencia T-275, 1994)". En principio, una decisión es justa si guarda relación con el principio 
de congruencia. Pero una decisión justa es aquella en la que existe una gran aproximación a la verdad, entendida esta como la correspondencia de los hechos ocurridos en la transformación de la realidad y los hechos que son del resorte probatorio en el proceso particular. El derecho fundamental de acceso a la justicia determina el compromiso del juez en busca de la verdad, si esto no fuera así, se podría decir, entonces, que el derecho procesal se torna perverso, porque afecta la posibilidad de la justicia. Hay que darle al derecho procesal el lugar que le corresponde, no solo el carácter de instrumental, sino el que en verdad tiene, el derecho procesal tiene un compromiso con la justicia (Montero, Ortellis \& Gómez, 1989, p. 221). El juez tiene que llegar a la verdad para poder decidir de manera justa (Ferrajoli, 2010, p. 22), y para ello cuenta con los medios de prueba, y por lo tanto, tiene la obligación de hacer una correcta valoración de los mismos, porque de esa manera garantiza la contradicción que es soporte fundamental del debido proceso; una verdadera valoración permite que si la parte no está de acuerdo, pueda solicitar la revisión de la legalidad del fallo, con la interposición de los recursos que para el caso correspondan (Corte Constitucional, sentencia C-143, 1993). Bajo el entendido de que el proceso es un instrumento para llegar a la justicia a través de la verdad, se imbrican las medidas cautelares como respuesta a las exacciones y sed de credibilidad, de legitimidad y de ejecutividad de las decisiones del sistema judicial. Siguiendo estos mismos argumentos, se destaca la siguiente frase de Emmanuel Levitas, "la verdad supone la justicia" que solo puede darnos a entender que la aptitud de proceso judicial depende de la posición que se asuma ante la verdad (citado por Vargas, 2012, p. 35).

c) Correspondencia con las normas procesales. Que no se incurra en moras o en dilaciones injustificadas y que se respete el debido proceso. El derecho de acceso a la justicia involucra que ella sea pronta y cumplida, el tiempo es también condicionante de la eficacia en la justicia. Sin embargo, no se puede decir con toda seguridad que las moras injustificadas en la tramitación de los procesos sea culpa exclusiva de los operadores jurídicos, es menester tener en cuenta en ciertas ocasiones pautas como: la complejidad del asunto, la misma actividad endoprocesal del interesado y la diligencia de las autoridades judiciales en la conducción del proceso.La Corte Constitucional frente a este punto dijo: "los pleitos interminables acaparan y obstruyen el aparato judicial y por lo tato impiden a otras personas acceder a la administración de justicia, causando simultáneamente daño al interés general" (Corte Constitucional, sentencia C-543, 1992). Quizás es uno de los puntos que con el uso de las medidas cautelares ha generado mayores reivindicaciones en el proceso, per se, en la misma justicia, ya que estas persiguen un propósito constitucionalmente relevante, como es asegurar la efectividad de la sentencia; es así como estas garantizan e irrogan protección real de derechos, lo que imprime eficacia práctica al proceso, eficacia que solo 
logra expresarse por la celeridad con que logran materializarse las disposiciones judiciales contenidas en las sentencias.

d) Que se produzca una sentencia de mérito, válida y más que esto, útil. Vale decir idónea para proteger los derechos afectados, la decisión debe ser justa, poner fin al litigio, pero se viola el derecho de acceso a la administración de justicia, si muy a pesar de la sentencia, las cosas siguen siendo iguales. Es decir que con la sentencia se transforme la realidad que llevó a la disputa de derechos entre asociados (Corte Constitucional, sentencia T-172, 1994). En este apartado hay que explicar que la instrumentalidad contenida en las medidas cautelares se manifiesta en la garantía de un derecho objetivo, en impedir la modificación de una situación de derecho o de hecho y asegurar los resultados de una decisión judicial o administrativa futura, mientras se adelante y concluya la actuación respectiva, situaciones que de otra forma quedarían desprotegidas ante la no improbable actividad o conducta maliciosa del actual o eventual obligado (Corte Constitucional, sentencia C-540, 1997).

e) Derecho a la ejecución de la sentencia en firme. Que se produzca una sentencia de mérito conforme al principio de prevalencia del derecho sustancial sobre el derecho procesal. Pero más que esto, no se puede hablar de garantías frente al acceso a la administración de justicia, si el Estado no hace lo necesario para que se materialice la decisión tomada por el juez. Así, de manera simple pero contundente, puede afirmarse con Zavala Baquerizo (1990, p. 155-157) que el objeto de la tutela cautelar judicial es la realización completa del derecho. Así mimo, en varias oportunidades la corporación constitucional se ha valido del derecho internacional para señalar que el cumplimiento de las medidas cautelares presenta como finalidad garantizar las resultas o efectos de un proceso actual o futuro en cuanto a la seguridad de las personas, de sus bienes o de las obligaciones. (Corte Constitucional, sentencia C-1064, 2000)

El fundamento último del derecho de acceso a la administración de justicia radica, en términos de la propia jurisprudencia de la Corte Constitucional, en obtener del Estado una solución justa a los conflictos que surgen en sus relaciones intersubjetivas, solución dada por un ente con capacidad jurídica, que sea ante todo imparcial, y sobre todo que la resolución de los conflictos sea definitiva y justa (Corte Constitucional, sentencia C-351, 1994). Y para que esto sea así debe darse en un plazo razonable que además contemple un momento procesal definitivo en el que con certeza las resoluciones que se profieran sean aptas para la concreción de los derechos (Corte Constitucional, sentencia C-543, 1992).

En resumen, siguiendo la misma línea jurisprudencial esbozada, el objeto de las medidas cautelares reside en asegurar el cumplimiento cabal de las decisiones 
adoptadas en el proceso, garantizar la presencia de los sujetos procesales y afianzar la tranquilidad jurídica y social en la comunidad; bajo esta premisa, de no procederse a su realización, su propósito puede resultar afectado por la demora en la decisión judicial (Corte Constitucional, sentencia C-774, 2001). En otros términos, el sistema de tutelas cautelares procesales garantiza la efectividad, la ejecutividad (firmeza) de las resueltas en la sentencia, al punto de que sin este, el proceso resultaría una quimera.

Una vez planteado lo anterior, se concluye que la realización de las garantías referenciadas se vivifica mediante la aplicación y ejercicio de las cautelas procesales, las cuales, en suma, corresponden a una efectiva manifestación de los valores del Estado constitucional. Como lo señala Menéndez Pérez (2004, p. 196), “el Estado de derecho se asienta cuando se logra la realización del derecho fundamental a la obtención de tutela judicial efectiva para cuya preservación, frente al mal endémico de la larga duración de los procesos, resulta imperativo que el compromiso del juez con los derechos fundamentales se evidencie con la aplicación de las medidas cautelares". Con fundamento en lo anterior, la demora en la tramitación de los procesos judiciales se invoca como razón principal para la previsión de mecanismos capaces de garantizar el cumplimiento efectivo de las decisiones judiciales adoptadas, ya que se ha demostrado que el afectado por una providencia puede adelantar acciones que permitan poner a buen recaudo sus bienes y colocarlos por fuera del alcance de la justicia o tomar medidas para que la sentencia que le sea adversa resulte imposible de ejecutar, así razonadamente los distintos ordenamientos jurídicos han instituido dispositivos para prevenir esas afectaciones al bien o al derecho controvertido, a fin de evitar que la decisión judicial sea vana, y esos dispositivos no son otros que las medidas cautelares, mediante las cuales el ordenamiento protege preventivamente a quien acude a las autoridades judiciales a reclamar un derecho, en virtud de responder a los principios de una justicia material, consiguiendo el acatamiento y guarda a la decisión judicial. Así mismo, el tiempo que trascurre en la iniciación del proceso y emisión de la sentencia se muestra como la oportunidad propicia para la ocurrencia de hechos que dificulten en gran medida el cumplimiento de lo decidido, ese peligro entendido como las circunstancias que obstaculizan la realización de una sentencia, lo cual impone la necesidad de ordenar medidas cautelares. Por consiguiente, resulta de extrema conveniencia la implementación de dispositivos procesales que oportunamente contraataquen las maniobras encaminadas a impedir la eficacia de la decisión, mecanismos que centren su objeto en la especial protección de derechos. Bajo esta premisa se abre paso el uso de dichas medidas desde la apertura del trámite procesal o incluso desde antes, para imposibilitar cualquier actuación capaz de entorpecer el cumplimiento de las decisiones jurisdiccionales. Es bien sabido que la excesiva dilación en la solución de los pleitos no solo genera justicia tardía, sino algo aun más grave, justicia ineficaz (Rojas, 2013, p. 335-340). 
Derecho $₹$ Realidad

En conclusión, las tutelas cautelares conforman parte integrante del contenido constitucional protegido del derecho de acceder a la justicia, un acceso que devengue en la efectividad del contenido sustancial de las sentencias, coadyuvándose así mismo la conquista de un equilibrio procesal, que en últimas es la finalidad del sistema procesal, incluido como forma de legitimación estatal. En este orden de ideas, resulta pertinente argüir la correspondencia del régimen de la tutela cautelar judicial con el apotegma de seguridad jurídica, que concentra esta última, cumplimiento, verdad y justicia (Vargas, 2012).

\section{Aproximación conceptual de las tutelas cautelares procesales}

Indudablemente, la denominación de cautela presenta multiplicidad de acepciones, las cuales concuerdan en la precaución o seguridad de lo que se quiere proteger o se pretende cubrir con el poder jurídico que la ley profiere. Así, el verbo cautelar referencia una medida destinada a prevenir la consecución de determinado fin o precaver lo que pueda dificultarlo (Carneluti, 1942, p. 62). Otros autores, como López Peñaranda (1998, p. 7-8) definen las medidas cautelares como actos procesales autónomos que sirven para afianzar las resultas de una decisión que se vaya a tomar en el proceso, es decir, son aquellas que tiene un carácter principalmente asegurativo. Otro significado corresponde "al remedio arbitrando por el derecho para obviar de alguna manera los riesgos de la duración temporal del juicio en orden a su eficacia" (Ramos, 1997, p. 723).

Por otro lado, en armonía con las normas internacionales, es pertinente traer a colación el artículo $1^{\circ}$ de la Convención Interamericana sobre el Cumplimiento de Medidas Cautelares, que dispone que las expresiones, medidas cautelares, medidas de seguridad o medidas de garantía son equivalentes cuando se utilizan para indiciar todo procedimiento o medio que tienda a garantizar los resultados o efectos de un proceso actual o futuro; tal normatividad permite colegir la importancia pragmática circunscrita en las cautelas procesales, ya que son concebidas en los diferentes ordenamientos jurídicos, tanto de culturas jurídicas continentales europeas y en las propiamente anglosajonas, como instrumentos que irrogan verdadera idoneidad y efectividad a los procedimientos judiciales. Finalidad compartida por el doctrinante Chinchilla Marín, ya que este las designa como "el instrumento útil para evitar el peligro de que la justicia pierda su eficacia, las cuales permiten alcanzar que el derecho declarado en la sentencia se materialice íntegramente" (Chinchilla, 1991).

Por las designaciones et supra, se destaca que con las medidas cautelares se protege la probabilidad de un poder jurídico radicado en cabeza del interesado. En análoga reflexión, la Corte Constitucional ha considerado que las medidas cautelares son actos o instrumentos propios del proceso mediante los cuales el juez está en condiciones de adoptar las medidas necesarias, en orden a garantizar la satisfacción 
de un derecho material o para su defensa a lo largo del proceso (Corte Constitucional, sentencia C-431, 1995). Con posterioridad y en forma más detallada, esta misma corporación ha dicho que "las medidas cautelares constituyen actos jurisdiccionales de naturaleza preventiva y provisional que, de oficio o a solicitud de parte, que ejecutan sobre personas, bienes y medidas de prueba para mantener respecto a estos un estado de cosas similar al que existía en el momento de iniciarse el trámite judicial, buscando la efectiva ejecución de la providencia e impidiendo que el perjuicio ocasionado por la vulneración de un derecho sustancial se haga más gravoso como consecuencia del tiempo que tarda el proceso en llega a su fin" (Corte Constitucional, sentencia C-925, 1999).

Por su parte, la doctrina ha continuado esta línea de pronunciamientos. López Blanco (2012, p. 1071), por ejemplo, señala que las medidas cautelares son providencias que, de oficio o dispositivamente, adopta el juez, tendientes asegurar el cabal e íntegro cumplimiento de las determinaciones judiciales.

Finalmente, Calamandrei (1964, p. 737) habla de medidas conservativas y de medidas innovativas, mediante las primeras se trata de evitar una modificación de la situación preexistente que impida u obstaculice la ejecución; las segundas se dirigen a generar una modificación en el estado de cosas, cuando ello es necesario para asegurar la eficacia práctica de la sentencia. Las dos clases de medidas intentan asegurar la efectividad de la resolución principal, pero difieren en el aspecto objetivo y subjetivo de la eficacia respectivamente.

Sin embargo, otros autores como Couture (1992, p. 320-325) establecen el término sentencias cautelares, pues debido a su variada terminología se llaman indistintamente, providencias cautelares, medidas de seguridad, medidas precautorias, medidas de garantía, acciones preventivas, medidas cautelares, resoluciones cautelares, tutelas cautelares, etc., que permiten prever un tinte caliginoso en su nominación, respecto de lo cual cabe aclarar que la diferencia que pueda existir entre providencias y sentencias o resoluciones corresponde a las modalidades de cada derecho positivo; dadas estas circunstancias, corresponde asentar el vocablo de providencias por su espectro legal extensivo, ya que abarca indistintamente toda clase de resoluciones judiciales. Así mismo, la determinación de medidas, dispositivos, tutelas, arriban al carácter instrumental esencial de las cautelas.

\subsection{Clasificación de las medidas cautelares}

Presentadas tales acepciones, que buscan una aproximación conceptual al divergente régimen de las cautelas procesales, es conveniente señalar la clasificación de estas mismas, a la luz del derecho comparado, aunque dejando en claro que el sistema 
de las medidas cautelares se muestra bastante disperso ya que han sido clasificadas bajo disímiles criterios (Devis, 1979, p. 178), ya sea atendiendo al tratamiento legal que reciben, o al efecto inmediato que producen, o al objeto sobre el cual recaen. Por el primer criterio se les clasifica como nominadas e innominadas, según que estén o no expresamente señaladas y reguladas en el ordenamiento; por los efectos que producen se distinguen en conservativas e innovativas, capaces de producir una modificación provisoria en la situación preexistente o mantienen tal situación; y por el objeto sobre el cual recaen, se clasifican en reales y personales, dependiendo si se practica sobre bienes o personas. Por otro lado, Carneluti (1942) consigna la siguiente categorización, a) proceso cautelar inhibitorio, b) proceso cautelar anticipatorio y c) proceso cautela restitutoria.

Siguiendo la perspectiva del Código General del Proceso, las cautelas se pueden ordenar a instancia de parte o de oficio, dependiendo de si para ordenarlas se necesita de solicitud del interesado; también en medidas intraprocesales o extraprocesales, según el escenario en que haya que practicarlas (Rojas, 2013, p. 439).

Expuestas estas clasificaciones, nos concretamos en las medidas cautelares innominadas, las cuales emanan como respuesta a las apremiantes necesidades de justicia de la sociedades modernas, logrando instituir instrumentos tendientes a asegurar la efectivización de los derechos en la ley sustancial, indicando ello, el establecimiento de directrices de raigambre activista judicial (Corte Constitucional, sentencia T-406, 1992) en códigos procesales, abrogando facultades a los jueces para decretar medidas cautelares innominadas, verbigracia, el artículo 700 del Código Procesal Civil italiano de 1940, el artículo 938 del Código Procesal Civil alemán, los artículos 83 a 93 del Código de Procedimiento Civil de la República Federativa Soviética de Rusia, el artículo 15 del Código de Procedimiento Judicial sueco, así como el artículo 760 del Código de Procedimiento Civil japonés. De igual forma en los Estados Unidos de Norteamérica mediante la utilización de las figuras del injuction y contempt of court se adoptan medidas cautelares innominadas. También el artículo 998 del Código de Procedimiento Civil brasilero, el artículo 232 del Código Procesal Civil y Comercial de argentina; finalmente el artículo 590 del Código General del Proceso colombiano; disposiciones procesales que comprenden un sistema de medidas cautelares no taxativas, ya que la experiencia demostró que no siempre el legislador puede proveer las posibilidades infinitas que la realidad presenta, y por ello, en ocasiones, los mecanismos cautelares tradicionales no resultan efectivos para obtener los propósitos de aseguramiento que se requerían, estas circunstancias provocaron que los ordenamientos procesales modernos incorporaran en sus articulados normativos las medidas cautelares genéricas.

Uno de los primeros referentes de estas se encuentra en la Ordenanza Procesal austriaca de 1896, en la cual se manifiesta que: "delinear casos específicos y 
detallados de estas medidas sería renunciar a ofrecer la ley los medios para atender a todas las necesidades que puedan surgir de la variedad de la vida y del concurso fortuito de circunstancias deversas" (Conigilio, s.f., p. 321-322). Este referente histórico concluye que una taxativa fijación de cautelas procesales puede fácilmente, en muchos casos, frustrar el propósito del instituto y el juez podría llegar a encontrarse en una desagradable posición: la de tener que permanecer impedido de actuar y no poder proveer a las necesidades cautelares, sino con medios inadecuados (Fabregá, 1998, p. 229).

\subsection{Características principales de las cautelas procesales}

En cuanto a los rasgos característicos de las medidas cautelares, tanto nominadas como innominadas, se señalan los siguientes:

- Jurisdiccionalidad: partiendo del principio de que la eficacia de la función jurisdiccional del Estado radica en la utilidad que reporten las cautelas procesales, es necesario que su determinación y práctica se encomienden exclusivamente a quienes ejercen dicha función, en este contexto el Estado ejercita su función jurisdiccional, al converger con las medidas cautelares un ecuánime thelo, la efectiva actuación del derecho (Rojas, 2003, p. 358-360).

A partir del reconocimiento de esta característica, la Corte Constitucional ha adjudicado la práctica de estas a alcaldes, funcionarios de policía, entidades administrativas, en concordancia con el mandato de colaboración con la rama judicial. Aunque esta corporación ha dejado en claro que es al legislador al que le corresponde establecer las condiciones en que los particulares pueden excepcionalmente cumplir con la función de administrar justicia, como es el caso de los árbitros (Corte Constitucional, sentencia C-431, 1995).

- Instrumentalidad: las tutelas cautelativas buscan la materialización de una decisión jurisdiccional, con independencia de que la práctica de aquellas anteceda o sea concomitante o subsiguiente a la actuación procesal. En esta característica es necesario discutir si estos instrumentos procesales presentan carácter autónomo o dependiente del proceso principal. La tendencia más reciente parece inclinarse en favor de la autonomía, ya que estas constituyen verdaderos medios de garantías, son tutelas mediatas que sirven para garantizar la eficacia del funcionamiento de la administración de justicia (Chinchilla, 1991, p. 32); empero, otros autores defienden la medida cautelar como un medio al servicio jurisdiccional, es decir, del instrumento que es el proceso, de forma que este último se convierte en un presupuesto de aquella. Ahora bien, si se solicita y se obtiene la medida con antelación al proceso principal, la demanda de esta medida se convierte en una condición de subsistencia (Corte Constitucional, sentencia C-431, 1995). En suma, la cautela se instrumentaliza en función de la pretensión que se ha 
hecho valer, anticipando o asegurando la continuación de la ejecución en el caso de éxito de la demanda (Ramos, 1997, p. 724).

- Provisionalidad: la vigencia de una medida cautelar es, por su naturaleza, transitoria; la medida no es perpetua, está llamada a expirar; característica designada por la Corte como contingencial, en la medida en que son susceptibles de modificarse o suprimirse a voluntad del beneficiado con ellas o por el ofrecimiento de una contragarantía por el sujeto afectado y, desde luego, cuando el derecho en discusión no se materializa; como consecuencia, ellas se mantienen mientras persistan las situaciones de hecho o de derecho que le dieron lugar a su expedición (Corte Constitucional, sentencia C-187, 1999).

- Sumariedad: la realización de la medida se fundamentan en un conocimiento sumario o una apariencia del derecho y generalmente sin oír a la parte contraria, punto bastante álgido entre la finalidad de la cautela y el respeto por el debido proceso (Salamanca, 1984, p. 297). Aunque no se encuentra una posición jurisprudencial única frente a la tensión en cuestión, la Corte ha señalado que la práctica de medidas cautelares no vulnera el debido proceso en función del propósito de estas, como es de asegurar la efectividad de la sentencia, previniendo que el demandado pueda intentar sustraerse a los efectos de un fallo adverso (Corte Constitucional, sentencia C-490, 2000).

- Urgencia: dada la imposibilidad de obtener la protección por otros medios, debido a la eminencia del peligro que podría provocar un daño en el derecho o la situación por la cual recae la medida, se respalda la adopción de las tutelas cautelares procesales; la urgencia significa inmediatez, es decir, la rapidez necesaria para conjurar el peligro de insatisfacción del derecho de quien solicita la aplicación de la medida, de ese mismo modo se ha avalado la urgencia en las medidas cautelares, al manifestar que los ordenamientos jurídicos existen en gran medida como un reconocimiento de las imperfecciones del ser humano, que hace necesaria la imposición coactiva de ciertos comportamientos y del cumplimiento de determinadas obligaciones, precisamente porque es necesario pensar que algunas personas están dispuestas a no acatar esas pautas normativas (Corte Constitucional, sentencia C490, 2000).

- Mutabilidad: las medidas no son inalterables, son susceptibles de revocación, modificación o transformación, sujetas a las circunstancias que propiciaron su decreto, y su extinción depende del cumplimiento oportuno de las cargas procesales (Salamanca, 1984, p. 297).

- Preventividad: se traduce en la protección de un derecho sustancial o de una situación jurídica del daño que pueda sobrevenir sobre el retardo en el cumplimiento 
eficaz de la justicia (López, 1998, p. 9). Así, el objeto de las cautelas consiste en eliminar la posibilidad de un daño o impedir que por acción u omisión se produzca el daño temido; de esta manera, el peligro se previene con el ejercicio oportuno del remedio, que deriva de la aplicación de un efectivo instrumento que contraataque preventivamente el daño ocasionado (Corte Constitucional, sentencia C-1007, 2002).

\subsection{Presupuestos sustanciales de las medidas cautelares}

Las distintas legislaciones procesales supeditan la aplicación y práctica de las cautelas a la calificación de los siguientes condicionamientos, siendo provechoso aclarar que tal calificación ha sido deferida por regla general al legislativo y paulatinamente se ha venido confiriendo tal facultad al juez. El insigne tribunal constitucional ha tomado importantes referencias de la doctrina extranjera para indicar cuales son esos presupuestos sustanciales, a saber:

- Verosimilitud del derecho o apariencia del buen derecho (fumusbonisjuris): denuncia la presentación del derecho invocado con fundadas probabilidades de éxito en la sentencia de fondo, al menos en apariencia, con ello se exige la demostración por parte del peticionario de la probable existencia del derecho, aunque no de su certeza, pues por razón de la urgencia no habrá lugar sino a un examen superficial (Hernández, 1997, p. 24). Entonces, la medida se concede no porque quien la solicita ostente un derecho indiscutible, sino porque en principio su petición aparece como tutelable, mediante el otorgamiento de la medida cautelar; en otras palabras, el solicitante debe acreditar la necesidad de acudir al proceso, probando sumariamente alguna existencia y exigibilidad de la responsabilidad jurídica del demandado (Corte Constitucional, sentencia C-840, 2001).

De forma que para calificar la procedencia de las medidas cautelares se debe hacer un examen preliminar que permita calcular qué tantas probabilidades de éxito tiene la pretensión a la cual le deberán de servir, determinando si la utilidad de la medida es mayor o menor que el perjuicio que pueda ocasionar (Rojas, 2002, p. 222); se trata de acreditar una apariencia de buen derecho, sujeta a un juicio de verosimilitud y probabilidad (Calamandrei, 1964, p. 77). En esa evaluación se demanda una actividad probatoria por parte del solicitante de la medida, en todo caso su declaración resulta de una cognición limitada por parte del juez, el cual debe contar con elementos de prueba sólidos que razonablemente puedan respaldar su decisión de adoptar y practicar las medidas cautelares, pues de otra manera su decisión se tornaría arbitraria e injustificada y transgrediría los principios irrestrictos del Estado social de derecho (Corte Constitucional, sentencia C-1007, 2002).

Tal presupuesto impide el ejercicio abusivo de la medida, ya que existe ineludiblemente una base solida para obrar de conformidad con esa presunción. En 
el derecho comunitario ha sido entendido tal condicionamiento como el deber de evaluar sin prejuzgar la probabilidad de la procedencia del proceso principal (Pastor \& Van Ginderachter, 1993, p. 86-89).

- Existencia del peligro (periculum inmora): también considerado por cierto sector de la doctrina como el riesgo por la demora del trámite, y se explica en la posibilidad de que un daño se presente como consecuencia de un hecho natural o humano en contra de los intereses sustanciales o procesales del solicitante, riesgo que proviene de la demora propia de tramitación del proceso, ya que el tiempo que transcurre en la apertura del proceso y la emisión del fallo se muestra como la oportunidad propicia para la ocurrencia de ciertos hechos que trunquen el acatamiento de lo decidido, convirtiéndose la sentencia en una simple hoja de papel dada la imposibilidad de su ejecución. En efecto, el peligro que constituye el fundamento del instrumento cautelar no es otro que la demora del proceso a su terminación (Quiroga, 1991, p. 33).

Lo expuesto induce a pensar en la necesidad de practicar las medidas cautelares oportunamente, antes que el eventual afectado pueda realizar maniobras encaminadas en el impedimento de aquellas (Rojas, 2002, p. 223). En similar desarrollo, la Corte Constitucional señaló que el plazo que ocupa la tramitación de un proceso propicia la afectación de los derechos litigiosos, per se, hace ineficaz e incierto su protección, en cuanto que en la duración del mismo, estos derechos pueden resultar afectados por factores exógenos. Este tribunal agrega que ante la posibilidad real de contar con una justicia inmediata se han implementado en la mayoría de los estatutos procesales del mundo, incluido el nuestro, la llamadas medidas cautelares, preventivas o innovativas*, las cuales persiguen el equilibro procesal y salvaguardan la efectividad de la acción judicial, garantizando con ello los derechos de igualdad y acceso a la administración de justicia; derechos que se hacen nugatorios cuando la función jurisdiccional no se muestra eficaz y protectora (Corte Constitucional, sentencia C-925, 1999).

Así pues, para que la medida cautelar sea decretada, ese peligro se concreta en la potencia o idoneidad de un hecho para ocasionar el fenómeno de la pérdida o disminución de un bien, o el sacrificio o la restricción de un bien jurídico, el cual no debe ser considerado con relación a la situación que crea la decisión definitiva, sino con el evento, causa del daño (Fabregá, 1998, p. 38-39). En conclusión, debe existir un vínculo jurídico directo entre el posible efecto dañoso y el evento natural o humano que dificulte la ejecutividad, la firmeza o el incumplimiento de lo decidido.

A las medidas cautelares innovativas también se les denomina anticipatorias o santificativas, en cuanto que su práctica implica un especie de satisfacción anticipada de la pretensión, porque producen una alteración provisoria de la situación original. 
Desprendiéndose que la medida cautelar tiene sentido si hay un derecho que necesite protección provisional y urgente, a causa de un daño producido o de amenaza inminente de que se produzca; este peligro es el que cautelarmente trunca el objeto del proceso (Campo, 1997, p. 49); lo que bien es señalado por la Corte que "estas herramientas persiguen evitar, por lo menos de manera inmediata y de forma provisoria que se prolongue el desconocimiento del ordenamiento jurídico vulnerado en apariencia", lo cual ha sido definido por la doctrina como una medida para conjurar el periculum in mora (Corte Constitucional, sentencia C-379, 2004). En este apartado se exige una actividad probatoria por parte del solicitante, dirigida a demostrar que los daños son realmente irreparables o incluso irreversibles (Corte Constitucional, sentencia C-379, 2004); en todo caso, el fallado siempre tendrá la obligación de determinar cuando el derecho o la situación jurídica corren peligro por la mora judicial (García, 2005, p. 21).

- Urgencia: en primera medida se explica que este presupuesto no es compendiado por todos los autores, sin embargo se acredita su importancia en la medida que describe la no residualidad de la cautela, es decir, la imposibilidad de lograr la finalidad de prevención por medio diferente a la de la medida cautelar (Salamanca, 1984, p. 283). Por su parte, el juez debe establecer la urgencia respecto del derecho que se invoca, en las reglas jurídicas pertinentes y conforme a las afirmaciones de afección que alega el solicitante, siendo que si el derecho sustancial está asegurado o existe otro medio menos gravoso de asegurarlo, ergo, la medida debe ser denegada. En el derecho comunitario también encontramos la urgencia como presupuesto condicional a la procedibilidad de las medidas cautelares, la cual debe apreciarse con relación a la necesidad que exista de pronunciarse provisionalmente, a fin de evitar que la parte que solicita la medida provisional se le ocasione un perjuicio aun mayor del que por su calidad de demandante recobra.

- Interés público: la procedencia de la medida impone ponderar la irreversibilidad del daño, del solicitante frente al daño que pueda llegar a sufrir el interés general y equilibrar esos intereses encontrados; esto dependerá de la mayor o menos ostensibilidad y claridad con que se acredite el derecho invocado (Campo, 1997, p. 54-58).

- Contracautelas: son garantías propuestas para precaver las consecuencias nocivas que puedan derivarse de la actuación o situación procesal, sirven para evitar la materialización de actuaciones cuyas actuaciones adversas pueden ser graves (Rojas, 2003, p. 367). Así mismo, dado que la adopción de medidas cautelares puede afectar el ejercicio de derechos y, por consiguiente, ocasionar perjuicios, los cuales habrán de ser resarcidos si el afectado con las medidas no estaba racionalmente obligado a sufrirlos. Si bien las contracautelas, o también llamadas cauciones, no son consideradas en sí como presupuestos sustanciales de las medidas cautelares, 
se revela que así como se adoptan medidas para garantizar el cumplimiento efectivo de la sentencia cuyo contenido se prevé, también es bueno tomarlas para asegurarle al afectado el pago de la indemnización a que tiene derecho si la sentencia no resulta como se había previsto, consagrando una finalidad correlativa a la de las cautelas procesales.

La utilidad de estas descubre un régimen eficaz de medidas cautelares, pues el riesgo de causar un daño injustificado se sopesa en buena medida con la garantía de su resarcimiento oportuno, reduciéndose por tanto el temor de quedar indemne un daño injustificado (Rojas, 2002, p. 226-227).

\section{Propuesta}

En primera instancia se presenta el problema especial de la taxatividad de las medidas cautelares en el proceso contencioso administrativo, de esta forma se arriba a la extensión de las cautelas procesales innominadas de los procesos civiles a los procesos contenciosos administrativos; tal extensión se sustenta en la libertad que debería tener el juez para otorgar aquellas medidas cuyo discernimiento y cognición le indique que son las más convenientes, apropiadas e idóneas, comprendiendo tanto las que tienen efectos conservativos como aquellas con efectos innovativos, en consideración de los grandes avances y progresos proferidos en la incorporación de normas en las leyes de procedimiento que facultan al juez o a los distintos órganos jurisdiccionales la adopción de cautelas que considere necesarias y pertinentes a fin de garantizar la efectividad de las sentencias y con ello, lograr la reivindicación procesal, tan anhelada por la mayoría de los teóricos, dogmáticos y excelsos procesalistas. Ahora bien, se propone esta extensión en los procesos contencioso administrativos porque en estos nuestra legislación únicamente ha reconocido como medidas cautelares las típicas y nominadas, omitiendo contemplar protección cautelar respecto de las decisiones de la administración que denieguen la solicitud de los administrados o aquellas que prohíban el desarrollo de alguna actividad.

Seguidamente, para proponer alternativas viables frente a este caliginoso problema, que funda la afectación a la tutela jurisdiccional efectiva, se deben abordar perspectivas que involucren los derechos individuales de los accionantes y el interés general, justificado en la preservación de la seguridad jurídica y el fortalecimiento del status quoactione inherente de un Estado social, democrático y constitucional de derecho. Conviene recordar que para que la seguridad jurídica no sea una quimera, es imperante que los derechos sustanciales reconocidos por el ordenamiento jurídico, puedan efectivizarse, en palabras de Zagrebelsky, se vivifiquen, aun en contra de aquellos que pretendan desconocerlos o controvertirlos, concentrando la coacción de los aparatos jurisdiccionales, cuyas actuaciones se reputan eficaces mediante la aplicación de medidas cautelares innominadas. 
De esta forma, el proceso contencioso administrativo como herramienta de control de las administraciones públicas y el derecho de los ciudadanos a la administración de justicia efectiva no puede ser ajeno a los postulados principialistas (Parejo, 1983 , p. 301) de los procesos civiles, que consagran al proceso instrumento de justicia, per se, la ausencia de las medidas cautelares innominadas en los institutos administrativos, denudan el incumplimiento por parte del Estado de su deber de garantizar a sus administrados la materialización de los efectos de las sentencias, deber inserto en el alcance fundamental del principio de la tutela jurisdiccional efectiva, ya que este, como se ha expuesto, no solo comprende el derecho a la jurisdicción (derecho de acción) y el debido proceso, sino que se extiende a la eficacia y ejecutividad de las decisiones judiciales.

Por lo expuesto, la ley debe proporcionar a los justiciables un régimen de tutelas cautelares que les aseguren los efectos de las sentencias para que sus intereses no se vean burlados después de un proceso dispendiosos y dilatado, de manera que cuando el conflicto con el Estado sea finalmente resuelto por medio de una sentencia, esta todavía tenga vigencia y genere una sensación de justicia en sus destinatarios. En este mismo sentido, si la razón de ser de las medidas cautelares es evitar la consumación de un daño jurídico producto de la pasmosa lentitud operativa del sistema judicial, el panorama es desalentador en el proceso contencioso administrativo, ya que para este se ha previsto un régimen cautelar judicial restrictivo, que a pesar de la existencia de mecanismos constitucionales de protección especial de los derechos fundamentales -acción de tutela- los administrados que se ven obligados a acudir por la vía judicial ordinaria a la jurisdicción contenciosa administrativa, no disponen de medidas distintas a las indicadas al artículo 230 de la ley 1437 del 2011.

La insuficiencia de este régimen cautelar nominado hace que este sea incapaz de hacer frente a la inactividad de la administración o a la denegación por parte suya de las peticiones que se hayan presentado ante ella, máxime si se tienen en cuenta los progresivos incrementos en la congestión en los procesos tramitados en esa jurisdicción especializada. Si bien se han adoptado mecanismos que han contribuido a disminuir el atraso y la mora judicial, es ineluctable la existencia de medidas cautelares innominadas que complementen los deberes judiciales, reactivando la función jurisdiccional del Estado, y proporcionando a los ciudadanos dispositivos procesales que aseguren el cumplimiento de lo dispuesto en las prohibidencias judiciales; estas medidas son, entonces, un requerimiento imperioso a fin de no solamente garantizar la eficacia de las decisiones en el interés de los accionantes sino trascender esos intereses individuales como una forma de preservar la seguridad jurídica, la cual debe entenderse como elemento indispensable para el desarrollo de un país. 
Reiterando que las medidas cautelares aportadas por el CPACA son insuficientes para satisfacer plena e integralmente el derecho a la tutela jurisdiccional efectiva, pues carecen de eficacia frente a actos de limitación negativos, como la denegación de una licencia, cuando lo que se pretende de la administración es una actuación positiva, ergo, es inexorable la exigencia de otros instrumentos de protección cautelar de los derechos de los administrados frente a la inactividad de la administración o actividad arbitraria en sinnúmero de situaciones.

Nuestro sistema jurídico que en paralelo con el francés, el alemán, e incluso el italiano, ha mantenido la tradicionalidad del régimen cautelar, soslayando directamente la justicia, ya que en muchas ocasiones el contenido de la sentencia se ha hecho ilusorio. En este punto, ante la enfermedad del incumplimiento sistemático de las sentencias, el profesor Manuel Restrepo Medina expone que las medidas cautelares innominadas o innovativas actúan como una serie de medicina, por ello, los tribunales no deben contentarse con solo decir el derecho, sino que también, deben asegurarse que lo dicho en el papel de la sentencia o en la resolución se traduzca en la realidad de los hechos. En efecto, de nada sirve obtener una sentencia favorable, cuando en la realidad de los hechos esa sentencia no se ejecutará, la sentencia no es una hoja de papel sin ningún valor jurídico que demande su cumplimiento o ejecución ni tampoco es una hoja de papel para envolver pescado; de manera que la única alternativa que busque la materialización de una sentencia judicial recae en las tutelas cautelares innominadas, y es allí donde se relata el impacto del référé administrativo (figura del derecho francés), procedimiento por medio del cual a petición del interesado se adopta cualquier medida útil, en caso de urgencia, siempre que no haya prejuzgamiento y que obviamente obre un asunto en litigio, efigie que puede ser de utilidad para definir un marco amplio e innominado de las medidas cautelares dentro de los procesos contencioso administrativos. En igual sentido, la legislación alemana dispone de las órdenes provisionales einstweilige Anordnungs-, medidas que pueden dictarse cuando exista peligro de que un cambio de las circunstancias presentes pueda malograr o dificultar sustancialmente el derecho del interesado o cuando sea necesaria una regulación provisional para prevenir prejuicios sustantivos o evitar daños. Así mismo, el caso italiano demuestra un gran avance, al disponer que el juez pueda dictar medidas positivas de sustitución de medidas arbitrarias de la pretensión del accionante por parte de la administración.

Todo lo anterior hace inadmisible la no extensión de las medidas cautelares innominadas a esta clases de procesos, suponiendo por tanto, una degeneración anticipada y sin remedio de justicia, completamente en contravía de los postulados consagrados en el artículo 2 de nuestra Carta Magna. Por su parte, en el ordenamiento español también se encuentra refugio a la aplicabilidad de un sistema atípico de medidas cautelares. Así, en la ley de enjuiciamiento civil se contiene una cláusula 
abierta que permite al juez adoptar las medidas que según las circunstancias fueren necesarias para asegurar la efectividad de la sentencia.

Si bien existe la revisión genérica del Código de Procedimiento Administrativo y de lo Contencioso Administrativo, al Código General del Proceso, para la regulación de aquellos aspectos no contemplados por aquel y que siempre que sean compatibles con la naturaleza de los procesos y actuaciones que se tramitan en esta jurisdicción especializada, el CPACA no contempla una cláusula abierta o general como la que sí trae la ley 1564 del 2012, limitándose a establecer como medidas cautelares las enlistadas en el artículo 230 ya mencionado. En tal virtud, la necesidad de arbitrar medidas que proporcionen una protección adecuada al titular del derecho reclamado judicialmente y asegure la total efectividad del pronunciamiento judicial que en definitiva se adopte, hace que la tutela cautelar judicial innominada se imponga como mecanismo idóneo para satisfacer plenamente el derecho iusfundamental de obtener una tutela jurisdiccional efectiva, per se. El legislador colombiano debe proporcionar esas medidas en procura de evitar el estado de indefensión de los administrados cuando se enfrentan a actos de la administración negativos o inicuos. Obviamente, medidas caracterizadas por la instrumentalizad, la provisionalidad y la mutabilidad que implica la exclusión de su posibilidad en eventos en los cuales su concesión cree un estado irrecuperable o gravemente lesivo en términos de la proporcionalidad al derecho reclamado.

Finalmente, la propuesta de adoptar o extender el sistema cautelar innominado en los procesos contenciosos administrativos, más que todo medidas cautelares positivas o aquellas que propendan a la creación de un modus vivendi nuevo entre las partes, que coadyuvan al fin de disminuir el peligro que representa el extenso desarrollo del proceso, asegurando los efectos de la sentencia en caso de ser favorable para el actor y que a su vez preserva la seguridad jurídica que encumbra el reflejo del interés general aunado al interés individual de los accionados. La importancia jurídica de esta propuesta recobra su reflexión en la íntima conexión existente entre las medidas cautelares innominadas y el derecho a la tutela jurisdiccional efectiva, ya que aquellas son la sustancia misma para que los administrados conservemos el espíritu de confianza en las instancias judiciales, el sentimiento de encontrarnos respaldados por un Estado social de derecho que tiene como finalidad preservar los intereses y derechos, de tal forma que cuando se dicta una sentencia, esta pueda tener todavía una vigencia y genere sensación de justicia en sus destinatarios, puesto que garantizados los efectos de la sentencia resultante no se podrá alegar que la tutela jurisdiccional no ha sido efectiva.

Bajo esta argumentación, el segundo punto de nuestra propuesta radica en la necesidad de ampliar la potestad cautelar genérica del juez, dentro de una regulación legal flexible, que establezca las consecuencias de la no adopción de estas medidas, 
exigiendo correlativamente la motivación de la decisión sobre el derecho o la negación de las medidas cautelares, como antonomasia de un sistema de administración de justicia democrático. $\mathrm{Al}$ respecto, se expone que si bien la ley ha de prever la existencia, la posibilidad de los presupuestos de las cautelas de conformidad con el principio de legalidad para una mejor garantía de los derechos que puedan verse afectados por la demora del trámite judicial, es imperante la necesidad de ampliar la potestad cautelar genérica de los jueces, donde se permite traer a colación algunos avances en materia ambiental y agraria, en las acciones populares y de tutela, e incluso en materia comercial, donde las facultades dispositivas y oficiosas del juez en el decreto de medidas cautelares atípicas han logrado garantizar en el mayor grado posible de certeza la eficacia de la sentencia. Este imperativo se hace más exigente en un Estado como el nuestro, caracterizado por la materialización de la justicia formal, convertido en un requerimiento, ya que una orden plasmada en el papel sin que se logre ejecutar, deja intacta e indemne la situación de vulneración de derechos.

Es así como la ejecución in natura de la sentencia deja al juez en libertad de otorgar aquellas medidas cuyo discernimiento le indique que son más convenientes, que hilvanan las exigencias de la aptitud de procedimiento judicial administrativo. Esta habilitación comprende la posibilidad de decretar medidas con efectos innovativos, creando un modus vivendi nuevo, que se acompasa con la exigencia imperativa de la motivación de la decisión como garantía de una justicia democrática, es decir, que la providencia por la cual se adopte la medida contenga una motivación suficiente sobre los presupuestos para su aplicación, especialmente el fumusbonisjuris y el periculum in mora; por consiguiente, la falta de motivación o la motivación insuficiente debe constituir un elemento de démerito en la valoración, determinando así, el margen de la discrecionalidad y habilitación que tiene el juez en el decreto de la medida innovativa. Igualmente no puede perderse de vista la aplicación de criterios como la proporcionalidad y ponderación, ya que la atribución de ponderar la procedencia de las medidas cautelares debe condicionar su ejercicio a la realización de un juicio sobre proporcionalidad de la medida preventiva, asegurativa o autosatisfactiva, en relación con la limitaciones que la misma impone a los derechos del demandado y el tiempo previsible en que dichas limitaciones se mantendrán en vigencia, calculando los niveles de afectación. Se sistematiza en la flexibilización de la regulación legal para el ejercicio de la potestad cautelar genérica judicial, lo que conduce a desvincular del poder cautelar del juez figuras típica prefijadas, otorgándole mayores poderes que, según las particularidades de cada caso, puedan conceder la tutela provisoria adecuada, asegurándose así la inmutabilidad de la situación de hecho o de derecho durante el transcurso del proceso, para preservar la igualdad de las partes y evitar la violación de sus derechos frente a una amenaza objetiva y actual. 


\section{Conclusiones}

La importancia de las medidas cautelares innominadas se refleja en la eficacia pragmática de la sentencia, por su utilidad como instrumento que asegura la efectiva aplicación del régimen jurídico a través del proceso judicial. De forma que se convierten en la garantía del imperio normativo, pues un adecuado régimen de medidas cautelares es la herramienta idónea para proteger a quien busca la tutela jurisdiccional de las consecuencias adversas que pueden producirle el transcurso del tiempo o eventuales actos fraudulentos (López, 2012, p. 1022), pero también este puede erigirse como factor determinante de la vigencia de un sistema normativo, es decir, seguridad jurídica, en cuanto es útil para mostrar la efectividad de los fallos.

Se agrega a la importancia empírica de las medidas cautelares innominadas, el reconocimiento del derecho. El amparo real y efectivo de los intereses legítimos se alcanza mediante las cautelas procesales, puesto que la aptitud del proceso judicial como instrumento de protección, desde el punto de vista empírico, se mide por la frecuencia con la que logran realizarse las disposiciones contenidas en las decisiones judiciales, en lo que mucho depende de la prontitud con que afloren estas. Cuanto más demore el pronunciamiento de un fallo, tanto menor será la posibilidad de materializarlo y mayor el descrédito del sistema judicial y el consecuente recurso de la autotutela, e incluso la utilización de mecanismos alternos y legítimos, ya que la escasa confianza del pueblo colombiano en el uso de las vías judiciales o de derecho, se sustenta en la pasmosa lentitud operativa. Fallas instrumentales que marcan el tapiz de cosas institucionales, convirtiéndose en ejes móviles de recurrencia a métodos ilegítimos de defensa, como el ajusticiamiento por organizaciones criminales, pues, hasta ahora, la justicia colombiana está catalogada como una de las seis más lentas del mundo. Por ello, la transcendencia pragmática y la importancia empírica de las medidas cautelares centran su atención y finalidad en la conquista de un sistema judicial efectivo que salvaguarde materialmente los derechos y permita el fortalecimiento del estatus activo de nuestro Estado social, democrático y constitucional de derecho.

En suma, se retoma el siguiente postulado instituido en sentencia T-172 de 1994: “...el juez, como expresión del Estado, acude en ayuda de las personas y les indica la forma adecuada y apropiada para que sus derechos no sean conculcados". Se cumple así el mandato constitucional de ACCESO REAL A LA JUSTICIA. Un acceso tiene que producir efectos útiles, logrados mediante la implementación de esta clase de medidas. 


\section{Referencias}

Alterini, A. (1993). La inseguridad jurídica, Buenos Aires: Abeledo Perrot.

Calamandrei, P. (1964). Providencias cautelares. S. Sentís (trad.). Buenos Aires: Editorial Bibliográfica.

Campo, J. M. (1997). Perspectiva de las medidas cautelares en el proceso contencioso administrativo. Bogotá: Universidad Externado de Colombia.

Capograssi, G. (1950). Proceso, ciencia y verdad. Madrid: s.n.

Carneluti, F. (1992). Instituciones del nuevo proceso italiano. J. Guasp (trad.). Barcelona: Bosh.

Chinchilla, C. (1991). La tutela cautela en la nueva justicia administrativa. Madrid: Civitas.

Corte Constitucional. (1992). Sentencia T-406/92. M.P. Ciro Angarita Barón. Expediente T-778.

Corte Constitucional. (1992). Sentencia C-543/92. M.P. José Gregorio Hernández Galindo. Expedientes D-056 y D-092.

Corte Constitucional. (1992). Sentencia C-221. M.P. Alejandro Martínez Caballero. Expediente D-006.

Corte Constitucional. (1992). Sentencia T-006. M.P. Eduardo Cifuentes Muñoz. Expediente T-221.

Corte Constitucional. (1993). Sentencia T-484. M.P. José Gregorio Hernández Galindo. Expediente T-16678.

Corte Constitucional. (1993). Sentencia C-143. M.P. José Gregorio Hernández Galindo. Expediente D-193.

Corte Constitucional. (1994). Sentencia T-275. M.P. Alejandro Martínez Caballero. Expediente T-31.551.

Corte Constitucional. (1994). Sentencia T-172. M.P. Alejandro Martínez Caballero. Expediente T-16336.

Corte Constitucional. (1994). Sentencia C-351. M.P. Hernando Herrera Vergara. Expediente D-503.

Corte Constitucional. (1995). Sentencia C-084. M.P. Alejandro Martínez Caballero. Expedientes D-648 y D-650.

Corte Constitucional. (1995). Sentencia C-431. M.P. Hernando Herrera Vergara. Expediente D-870. 
Corte Constitucional. (1997). Sentencia C-540. M.P. Hernando Herrera Vergara. Expediente T D-1667.

Corte Constitucional. (1999). Sentencia C-925. M.P. Vladimiro Naranjo Mesa. Expediente D-2407.

Corte Constitucional. (1999). Sentencia C-187. M.P. Martha Victoria Sáchica de Moncaleano. Expediente. L.A.T.-121.

Corte Constitucional. (2000). Sentencia C-490/00. M.P. Alejandro Martínez Caballero. Expediente D-2650.

Corte Constitucional. (2000). Sentencia C-1064. M.P. Álvaro Tafur Galvis. Expediente D-2793.

Corte Constitucional. (2001). Sentencia T-606/01. M.P. Marco Gerardo Monroy Cabra. Expediente T-402991.

Corte Constitucional. (2001). Sentencia C-774. M.P. Rodrigo Escobar Gil. Expediente D- 3271.

Corte Constitucional. (2001). Sentencia C-840. M.P. Jaime Araujo Rentería. Expediente D-3389.

Corte Constitucional. (2002). Sentencia C-1007. M.P. Clara Inés Vargas Hernández. Expediente R.E.121.

Corte Constitucional. (2004). Sentencia C-039/04. M.P. Rodrigo Escobar Gil. Expediente D-4664.

Corte Constitucional. (2004). Sentencia C-039/04. M.P. Rodrigo Escobar Gil. Expediente D-4664.

Corte Constitucional. (2004). Sentencia C-379. M.P. Alfredo Beltrán Sierra. Expediente. D-4974.

Couture, E. J. (1992). Fundamentos del derecho procesal civil. (3 $\left.{ }^{\mathrm{a}} \mathrm{ed}.\right)$. Buenos Aires: Depalma.

Devis, H. (1979). Pruebas judiciales. Tomo II, Compendio de derecho procesal. (6 ed.) Bogotá: ABC.

Fabregá, J. (1998). Medias cautelares. Bogotá: Gustavo Ibáñez.

Ferrajoli, L. (2010). Derechos y garantías. Madrid: Trotta.

García, E. (2005). Medidas cautelares. Introducción a su estudio. Bogotá: El Foro de la Justicia.

Hernández, V. (1997). La tutela judicial cautelar en el contencioso administrativo. Caracas: Vadell Hermanos. 
López, G. (1998). Extinción del dominio, alterabilidad y medidas cautelares en el proceso penal. Bogotá: Librería Jurídica Radar.

Menéndez, S. (2004). El proceso contencioso administrativo como instrumento de control de las administraciones públicas y el derecho de los ciudadanos a la justicia administrativa efectiva. En Cuadernos de Derecho judicial XII2003. Constitución y control de la entidad administrativa. Madrid: Consejo general del Poder Judicial.

Montero, J., Ortellis, M. \& Gómez, J. L. (1989). Derecho jurisdiccional, proceso civil, Tomo II. ( $2^{\mathrm{a}}$ ed.). Barcelona: Bosch.

Moreno, L. J. (2000). Acceso a la justicia. Bogotá: Ediciones Academia Colombiana de Jurisprudencia.

Palomino, J. (2011). Estudios de derecho procesal constitucional. Bogotá: Editores Ltda.

Parejo, L. (1983). Los postulados constitucionales de la reforma administrativa. Madrid: Civitas.

Pastor, B. \& Van Ginderachter, E. (1993). El procedimiento de medidas cautelares ante el tribunal de justicia y el tribunal de primera instancia de las comunidades europeas, Madrid: Civitas.

Pérez, J. (2000). Curso de derecho constitucional. (7 ed.). Madrid: Marcial Pons.

Porras, E. G. (2011). Acceso a la justicia vs acciones de tutela contra providencias judiciales. Tesis de maestría, Universidad Externado de Colombia, Facultad de Derecho, Bogotá.

Quiroga, H. E. (1991). Procesos y medidas cautelares. (2 ${ }^{\mathrm{a}}$ ed.) Bogotá: OKEY Impresores.

Restrepo, M. A. (2006). Perspectiva constitucional sobre la tutela cautelar judicial. Bogotá: Biblioteca Jurídica Universidad del Rosario, 2006.

Ramos, F. (1997). Enjuiciamiento civil. T.II. Barcelona: Bosh.

Rojas, M. E. (2002). Teoría del proceso. Bogotá: Universidad Externado de Colombia.

Rojas, M. E. (2003). El proceso civil colombiano. Bogotá: Universidad Externado de Colombia.

Rojas, M. E. (2013). Lecciones de derecho procesal. Tomo II. Procedimiento civil. (5 ed.). Bogotá: ESAJU.

Salamanca, G. (19849. Medidas cautelares en los procesos civiles y laborales. En O. Ardila. Contribuciones a la ciencia jurídica. Bogotá: Diana Colombiana.

Vargas, L. E. (2012). Una mirada constitucional al proceso civil. Colección Monografías, 21.

Zavala, J. E. (1990). El proceso penal, t. III. (3 ${ }^{\text {a }}$ ed.). Bogotá: Edino. 